\title{
Intensity-modulated radiation therapy in early stage squamous cell carcinoma of the larynx: treatment trends and outcomes
}

\author{
Rodney E. Wegner, Stephen Abel, John J. Bergin, Athanasios Colonias \\ Division of Radiation Oncology, Allegheny Health Network Cancer Institute, Pittsburgh, PA, USA
}

\author{
Received: December 6, 2019 \\ Revised: January 15, 2020 \\ Accepted: January 17, 2020

\section{Correspondence:} \\ Rodney E. Wegner \\ Division of Radiation Oncology, \\ Allegheny Health Network Cancer \\ Institute, 320 E. North Avenue, \\ Pittsburgh, PA 15212, USA. \\ Tel: +1-412-359-3400 \\ Fax: +1-412-359-3171 \\ E-mail: Rodney.wegner@ahn.org \\ ORCID: \\ https://orcid.org/0000-0003-2416-3499
}

Purpose: Definitive radiotherapy remains a primary treatment option for early stage glottic cancer. Intensity-modulated radiation therapy (IMRT) has emerged as the standard treatment technique for advanced head and neck cancers, whereas three-dimensional conformal radiotherapy (3D-CRT) has remained standard for early glottic cancers. We used the National Cancer Database (NCDB) to identify predictors of IMRT use and effect on outcome in these patients.

Materials and Methods: We queried the NCDB from 2004-2015 for squamous cell carcinoma of the glottic larynx staged Tis-T2N0 treated with radiation alone. Logistic regression was used to identify predictors of IMRT. Cox regression was used to identify factors predictive of overall survival. Propensity matching was conducted to account for indication bias.

Results: We identified 15,627 patients, of which 11\% received IMRT. IMRT use rose from 2\% in 2004 to $16 \%$ in 2015. Predictors of IMRT include: increased comorbidity, T2 stage, urban location, chemotherapy, treatment at an academic center, and later treatment year. Predictors of improved survival were female gender, higher income, lower stage, no chemotherapy, academic facility, and more remote year. There was no difference in survival between 3D-CRT and IMRT across all stages.

Conclusions: The rate of IMRT use for early stage glottic laryngeal cancer has increased over time. There was no difference in outcome in patients receiving IMRT versus 3D-CRT across the cohort.

Keywords: IMRT, Laryngeal cancer, Radiation therapy

\section{Introduction}

Early stage larynx cancer continues to affect up to 15,000 patients each year in the United States, with a resultant 3,000-4,000 deaths per year [1]. The main goal of treatment is larynx preservation, which can be achieved through several options including transoral laser stripping, partial laryngectomy, or definitive radiation therapy [2-4]. The true vocal cords possess minimal lymphatic drainage, with very low rates of occult lymph node disease. As such, regardless of primary treatment the neck nodal areas are typically observed [5]. With that in mind three-dimensional conformal radiotherapy (3D-CRT) has been the standard of care, with doses recommended from 63-70 Gy using 2-2.25 Gy/day [6,7]. With the ability to reduce toxicity through avoidance of surround- ing critical organs, intensity-modulated radiation therapy (IMRT) has gained widespread popularity and is currently standard of care in more advanced head and neck malignancies [8]. The ability to avoid surrounding structures has been extrapolated to early stage glottic larynx cancers, with the use of IMRT to avoid the carotid artery and hopefully prevent stenosis $[9,10]$. Despite that data, IMRT is still typically used sparingly. We thus sought to use the National Cancer Database (NCDB) to determine predictors and trends in the use of IMRT in early glottic larynx cancer, and if there was any effect on outcome.

\section{Materials and Methods}

We queried the NCDB from 2004-2015 for patients with Tis-T2N0 
squamous cell carcinoma (SCC) of the glottic larynx (the International Classification of Diseases for Oncology 3rd edition [ICD-0-3] code C32.0) that was managed without surgery, stripping, or ablation (all coded for in the NCDB). For inclusion, patients must have received neck radiation at a definitive dose (defined as 60-75 Gy) and have at least 2 months of documented follow-up. Radiation technique is recorded in the NCDB and patients receiving either 3D-CRT or IMRT were included. Fig. 1 is a CONSORT diagram outlining selection criteria. The data within the NCDB is maintained by Commission on Cancer of the American College of Surgeons. Of note, the NCDB datasets are completely de-identified and do not require Institutional Review Board approval for analysis. In addition, the Commission on Cancer of the American College of Surgeons have not verified and are not responsible for the analytic or statistical methodology employed, or the conclusions drawn from these data by the investigator. It is estimated that the NCDB captures approximately $70 \%$ of newly diagnosed malignancies each year from approximately 1,500 centers across the United States.

The NCDB contains a wide range of clinicopathologic and socioeconomic data points. Race was characterized as Caucasian, African American, or other. The widely accepted Charlson/Deyo Comorbidity Index was used for quantification of comorbid conditions [11]. Stage within this particular dataset was defined according to the 7th edition of the American Joint Committee on Cancer's clinical group. Socioeconomic data is provided as quartiles of the percentage of persons with less than a high school education and median household income based on zip code of residence. The facility type was assigned according to the Commission on Cancer accreditation category (community center, comprehensive community cancer center, and academic/research program). Locations were assigned based on population data provided by the US Department of Agriculture Economic Research Service. Insurance status is recorded in the dataset as it appears on the admission page and was separated into three categories: none, private, or governmental (Medicare and Medicaid).

Data were analyzed using MedCalc version 18 (MedCalc, Ostend, Belgium). Summary statistics are presented for discrete variables. Chi-square tests compared sociodemographic, treatment, and tumor characteristics between the treatment groups. Multivariable logistic regression was used to identify predictors of IMRT use. Overall survival was calculated in months from time of diagnosis to date of last contact or death, as is standard within the NCDB. Of note, local control, distant failure, and toxicity are not recorded within the NCDB. Multivariable Cox regression was used to determine predictors of survival [12]. Multivariable logistic regression was used to calculate a propensity score indicative of the probability of receiving IMRT [13]. This score was used to generate
Squamous cell carcinoma (SCC) of the glottis $(n=48,731)$

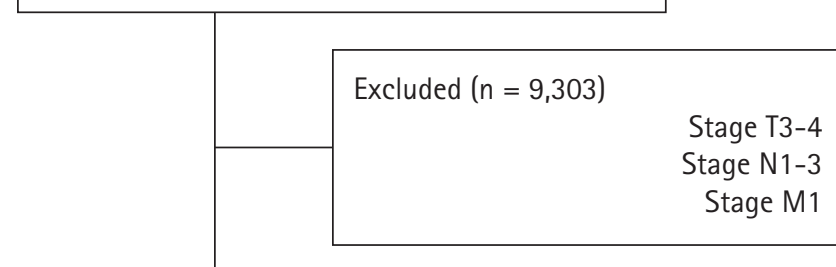

Early stage (Tis-T2 NO) SCC of the glottis $(n=39,428)$

Excluded $(n=16,291)$ No EBRT to Head and neck radiation dose (59.4 Gy - 75.0 Gy)

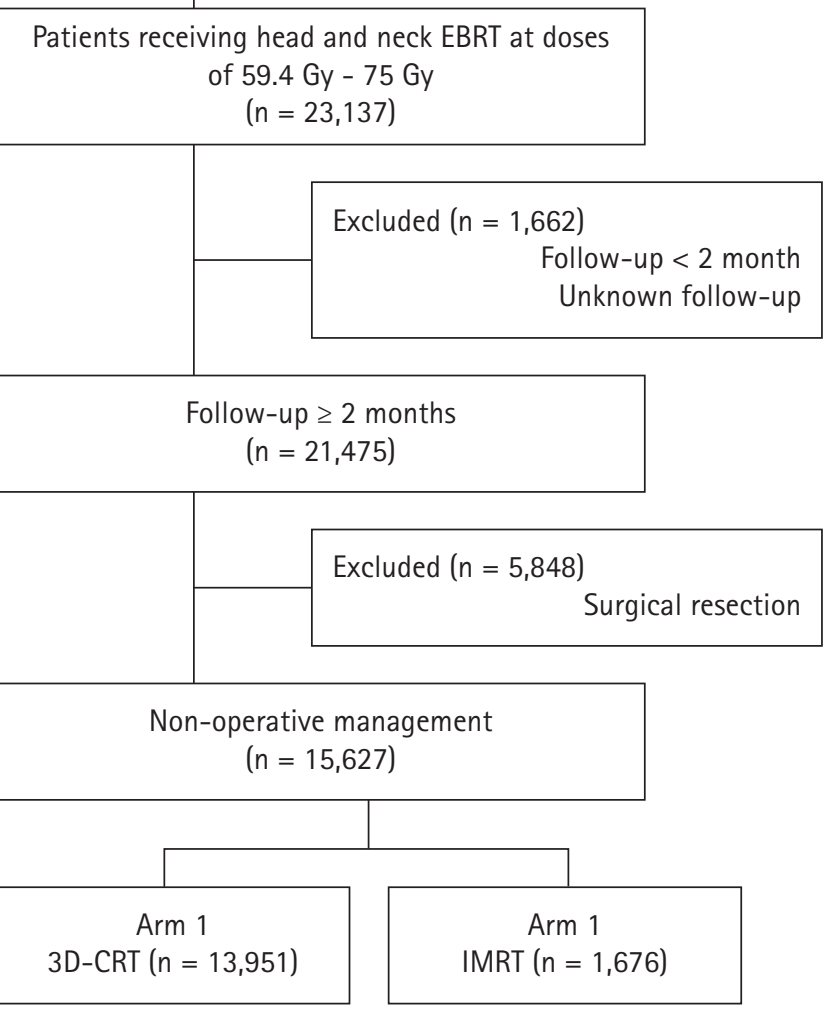

Fig. 1. CONSORT diagram showing selection criteria: radiotherapeutic technique in treatment of early-stage squamous cell carcinoma of the glottis. EBRT, external beam radiation therapy; 3D-CRT, three-dimensional conformal radiotherapy; IMRT, intensity-modulated radiation therapy.

a case control series matching pairs exactly on the propensity score, yielding 1,557 pairs. Kaplan-Meier curves were used on this propensity matched cohort to calculate cumulative probability of survival [14]. Log-rank statistics were used to test whether there was a statistically significant difference in the cumulative proportions across groups. 
Table 1. Patient baseline characteristics $(n=15,627)$

\begin{tabular}{|c|c|}
\hline Characteristic & No. $(\%)$ \\
\hline \multicolumn{2}{|l|}{ Age (yr) } \\
\hline$\leq 67$ & $8,254(53)$ \\
\hline$>67$ & $7,373(47)$ \\
\hline \multicolumn{2}{|l|}{ Chemotherapy } \\
\hline No & $14,913(95)$ \\
\hline Yes & $714(5)$ \\
\hline \multicolumn{2}{|l|}{ Comorbidity score } \\
\hline 0 & $12,467(80)$ \\
\hline 1 & 2,396 (15) \\
\hline$\geq 2$ & $764(5)$ \\
\hline \multicolumn{2}{|l|}{ Distance from facility (mile) } \\
\hline$\leq 11.5$ & $9,416(60)$ \\
\hline$>11.5$ & $6,211(40)$ \\
\hline \multicolumn{2}{|l|}{ Facility type } \\
\hline Community cancer center & $1,741(11)$ \\
\hline Comprehensive community cancer center & $7,176(46)$ \\
\hline Academic/research program & $6,555(43)$ \\
\hline \multicolumn{2}{|l|}{ Grade } \\
\hline Well differentiated & $2,836(28)$ \\
\hline Moderately differentiated & $6,196(61)$ \\
\hline Poorly differentiated & $1,172(11)$ \\
\hline \multicolumn{2}{|l|}{ Education (\% without a high school diploma) } \\
\hline$\geq 29$ & $3,542(23)$ \\
\hline $20-28.9$ & $4,405(29)$ \\
\hline 14-19.9 & $4,201(27)$ \\
\hline$<14$ & $3,214(21)$ \\
\hline \multicolumn{2}{|l|}{ Median income by zip code (US dollar) } \\
\hline$<30,000$ & $3,432(22)$ \\
\hline
\end{tabular}

\section{Results}

We identified 15,627 patients meeting above eligibility criteria, of which 1,676 (11\%) received IMRT. The median age was 67 years (range, 19 to 90 years) and the vast majority (95\%) were treated without chemotherapy. Table 1 contains a full list of baseline patient characteristics. The median dose for all patients was $66 \mathrm{~Gy}$ (range, 63 to $68 \mathrm{~Gy}$ ) in 33 fractions (range, 28 to 34 fractions). Of note, the median dose in the IMRT arm was $68 \mathrm{~Gy}$, compared to $66 \mathrm{~Gy}$ in the 3D-CRT arm ( $p<0.001$, independent t-test). The median time initiation of radiotherapy was 30 days (range, 22 to 41 days) in the non-IMRT arm and 36 days (range, 27 to 49 days) in the IMRT group ( $p=0.012$, independent t-test). The rate of IMRT use increased over time, from 2\% in 2004 to $16 \%$ in 2015 (Fig. 2). Regarding hypofractionation (dose/fraction, $>2.25$ Gy per fraction), $42 \%$ of patients received a hypofractionated regimen in the entire cohort, whereas $51 \%$ received a conventionally frac-

\begin{tabular}{|c|c|}
\hline Characteristic & №. $(\%)$ \\
\hline $30,000-34,999$ & $3,779(25)$ \\
\hline $35,000-45,999$ & $3,607(24)$ \\
\hline$\geq 46,000$ & $4,512(29)$ \\
\hline \multicolumn{2}{|l|}{ Insurance } \\
\hline None & $510(3)$ \\
\hline Private & $5,560(36)$ \\
\hline Government & $9,249(61)$ \\
\hline \multicolumn{2}{|l|}{ Location } \\
\hline Metropolitan & $12,323(81)$ \\
\hline Urban & 2,559 (17) \\
\hline Rural & 354 (2) \\
\hline \multicolumn{2}{|l|}{ Race } \\
\hline Caucasian & $13,414(86)$ \\
\hline African American & 1,783 (11) \\
\hline Other & $430(3)$ \\
\hline \multicolumn{2}{|l|}{ Gender } \\
\hline Male & $13,421(86)$ \\
\hline Female & $2,206(14)$ \\
\hline \multicolumn{2}{|l|}{ Stage } \\
\hline Tis & $1,876(12)$ \\
\hline $\mathrm{T} 1$ & $10,068(64)$ \\
\hline $\mathrm{T} 2$ & $3,683(24)$ \\
\hline \multicolumn{2}{|l|}{ Year group } \\
\hline 2004-2006 & $3,934(25)$ \\
\hline 2007-2009 & $3,896(25)$ \\
\hline 2010-2012 & $3,899(25)$ \\
\hline 2013-2015 & $3,897(25)$ \\
\hline
\end{tabular}

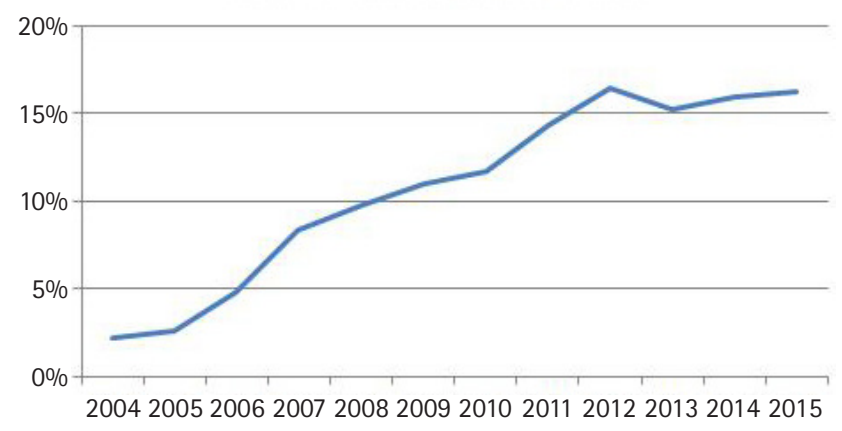

Fig. 2. Rate of IMRT use by year for early stage (Tis-T2N0) squamous cell carcinoma of the glottic larynx. Rates rose from $2 \%$ in 2004 to 16\% in 2015.

tionated ( $<2.25$ Gy per fraction) regimen. In patients receiving IMRT, 29\% received a hypofractionated regimen ( $p<0.001$, independent t-test), with $47 \%$ receiving convention fractionation. 
Table 2. Multivariable logistic regression for predictors of IMRT

\begin{tabular}{|c|c|c|c|c|c|}
\hline Characteristic & OR (95\% Cl) & p-value & Characteristic & OR $(95 \% \mathrm{Cl})$ & $p$-value \\
\hline Age (yr) & & & $35,000-45,999$ & $0.98(0.81-1.18)$ & 0.7918 \\
\hline$\leq 67$ & Reference & & $\geq 46,000$ & $1.17(0.95-1.44)$ & 0.1376 \\
\hline$>67$ & $0.89(0.78-1.01)$ & 0.0636 & Insurance & & \\
\hline Chemotherapy & & & None & Reference & \\
\hline No & Reference & & Private & $0.81(0.62-1.06)$ & 0.1278 \\
\hline Yes & $4.98(4.17-5.96)$ & $<0.0001^{*}$ & Government & $0.82(0.62-1.08)$ & 0.1614 \\
\hline Comorbidity score & & & Location & & \\
\hline 0 & Reference & & Metropolitan & Reference & \\
\hline 1 & $0.99(0.85-1.14)$ & 0.8738 & Urban & $1.21(1.02-1.42)$ & $0.0274^{*}$ \\
\hline$\geq 2$ & $1.28(1.03-1.60)$ & $0.0288^{*}$ & Rural & $1.25(0.87-1.80)$ & 0.2266 \\
\hline Distance from facility (mile) & & & Race & & \\
\hline$\leq 11.5$ & Reference & & Caucasian & Reference & \\
\hline$>11.5$ & $0.92(0.81-1.04)$ & 0.1650 & African American & $0.89(0.74-1.06)$ & 0.1800 \\
\hline Facility type & & & Other & $1.08(0.78-1.48)$ & 0.6499 \\
\hline Community cancer center & Reference & & Gender & & \\
\hline Comprehensive community cancer & $1.20(1.00-1.45)$ & 0.0564 & Male & Reference & \\
\hline & & & Female & $1.12(0.97-1.30)$ & 0.1288 \\
\hline Academic/research program & $1.35(1.11-1.63)$ & $0.0026^{*}$ & Stage & & \\
\hline Grade & & & Tis & Reference & \\
\hline Well differentiated & Reference & & $\mathrm{T} 1$ & $0.93(0.77-1.13)$ & 0.4665 \\
\hline Moderately differentiated & $1.05(0.90-1.23)$ & 0.5281 & $\mathrm{~T} 2$ & $2.12(1.74-2.59)$ & $<0.0001^{*}$ \\
\hline Poorly differentiated & $1.24(0.99-1.54)$ & 0.0572 & Year group & & \\
\hline $\begin{array}{l}\text { Education (\% without a high school } \\
\text { diploma) }\end{array}$ & & & 2004-2006 & Reference & \\
\hline$\geq 29$ & Reference & & 2007-2009 & $3.25(2.63-4.01)$ & $<0.0001^{*}$ \\
\hline $20-28.9$ & $1.03(0.88-1.20)$ & 0.7366 & 2010-2012 & $5.10(4.16-6.25)$ & $<0.0001^{*}$ \\
\hline $14-19.9$ & $0.98(0.81-1.17)$ & 0.8012 & 2013-2015 & $5.94(4.86-7.28)$ & $<0.0001^{*}$ \\
\hline$<14$ & $0.92(0.74-1.14)$ & 0.4556 & Dose per fraction (Gy) & & \\
\hline Median income by zip code (US dollar) & & & $\leq 2.0$ & Reference & \\
\hline$<30,000$ & Reference & & $>2.0$ & $0.78(0.70-0.88)$ & $<0.0001^{*}$ \\
\hline $30,000-34,999$ & $0.99(0.83-1.17)$ & 0.8681 & & & \\
\hline
\end{tabular}

IMRT, intensity-modulated radiation therapy; $\mathrm{OR}$, odds ratio; $\mathrm{Cl}$, confidence interval.

${ }^{*} p<0.05$, statistical significance.

On multivariable logistic regression predictors of IMRT use were receipt of chemotherapy, higher comorbidity score, treatment at an academic facility, T2 stage, fraction dose $\leq 2.0 \mathrm{~Gy}$, and more recent year of treatment (Table 2). On multivariable Cox regression, predictors of worse survival included: increased age, receipt of chemotherapy, higher comorbidity score, treatment at a community hospital, higher grade, lower income, male gender, higher T stage, and more remote year of treatment (Table 3). As described in the methods, a propensity score was generated based upon the results of multivariable logistic regression and included the following factors which were significant on logistic regression: age, chemotherapy, comorbidity score, facility type, location, T stage, and treatment year. Using propensity score there were 1,650 matches generated. Kaplan-Meier analysis on those 1,650 pairs revealed a median overall survival of 99 months compared to 93 months for 3D-CRT and IMRT, respectively ( $p=0.50$ ) (Fig. 3). When limited to $\mathrm{T} 1$ lesions there was no statistically significant difference in survival (Fig. 4A). When limited to T2 lesions (691 pairs), outcomes were again not significantly different: median survival of 76 months compared to 86 months ( $p=0.25$ ) (Fig. 4B).

\section{Discussion and Conclusion}

This study shows a steady increase in IMRT use for early stage SCC of the glottic larynx, from $2 \%$ to $16 \%$ by 2015 . Not surprisingly, patients treated at academic facilities were more likely to be treated with IMRT, which makes sense as the majority of research on this topic stems from those centers $[9,10]$. In addition, the use 
Table 3. Cox regression for predictors of survival

\begin{tabular}{|c|c|c|}
\hline Characteristic & $\mathrm{HR}(95 \% \mathrm{Cl})$ & $p$-value \\
\hline \multicolumn{3}{|l|}{ Age (yr) } \\
\hline$\leq 67$ & Reference & \\
\hline$>67$ & $1.85(1.73-1.97)$ & $<0.0001$ \\
\hline \multicolumn{3}{|l|}{ Chemotherapy } \\
\hline No & Reference & \\
\hline Yes & $1.46(1.31-1.64)$ & $<0.0001$ \\
\hline \multicolumn{3}{|l|}{ Comorbidity score } \\
\hline 0 & Reference & \\
\hline 1 & $1.29(1.20-1.38)$ & $<0.0001$ \\
\hline$\geq 2$ & $1.96(1.78-2.17)$ & $<0.0001$ \\
\hline \multicolumn{3}{|l|}{ Facility type } \\
\hline Community cancer center & Reference & \\
\hline $\begin{array}{l}\text { Comprehensive community cancer } \\
\text { center }\end{array}$ & $1.02(0.94-1.11)$ & 0.6300 \\
\hline Academic/research program & $0.91(0.86-0.96)$ & 0.0008 \\
\hline \multicolumn{3}{|l|}{ Grade } \\
\hline Well differentiated & Reference & \\
\hline Moderately differentiated & $1.08(1.02-1.14)$ & 0.0060 \\
\hline Poorly differentiated & $1.24(1.12-1.36)$ & $<0.0001$ \\
\hline \multicolumn{3}{|l|}{ Income (US dollar) } \\
\hline$<30,000$ & Reference & \\
\hline $30,000-34,999$ & $0.93(0.86-1.00)$ & 0.0658 \\
\hline $35,000-45,999$ & $0.86(0.80-0.93)$ & 0.0001 \\
\hline$\geq 46,000$ & $0.83(0.78-0.90)$ & $<0.0001$ \\
\hline \multicolumn{3}{|l|}{ Insurance } \\
\hline None & Reference & \\
\hline Private & $0.76(0.67-0.88)$ & 0.0001 \\
\hline Government & $1.14(0.99-1.30)$ & 0.0657 \\
\hline \multicolumn{3}{|l|}{ Gender } \\
\hline Male & Reference & \\
\hline Female & $0.86(0.80-0.93)$ & 0.0002 \\
\hline \multicolumn{3}{|l|}{ Stage } \\
\hline Tis & Reference & \\
\hline $\mathrm{T} 1$ & $1.04(0.95-1.13)$ & 0.3816 \\
\hline T2 & $1.45(1.36-1.54)$ & $<0.0001$ \\
\hline \multicolumn{3}{|l|}{ Year group } \\
\hline 2004-2006 & Reference & \\
\hline $2007-2009$ & $1.01(0.94-1.08)$ & 0.8705 \\
\hline 2010-2012 & $1.04(0.97-1.12)$ & 0.2942 \\
\hline $2013-2015$ & $1.11(1.02-1.21)$ & 0.0137 \\
\hline
\end{tabular}

$\mathrm{HR}$, hazard ratio; $\mathrm{Cl}$, confidence interval.

of chemotherapy (although that cohort was small) also predicted for IMRT use, perhaps indicating some other high risk features or need to electively treat nodal volumes (bulky tumors or impaired cord mobility); data which is unfortunately not included in the NCDB. In addition, patients treated with IMRT had a higher radiation dose compared to those treated with 3D-CRT, again poten-

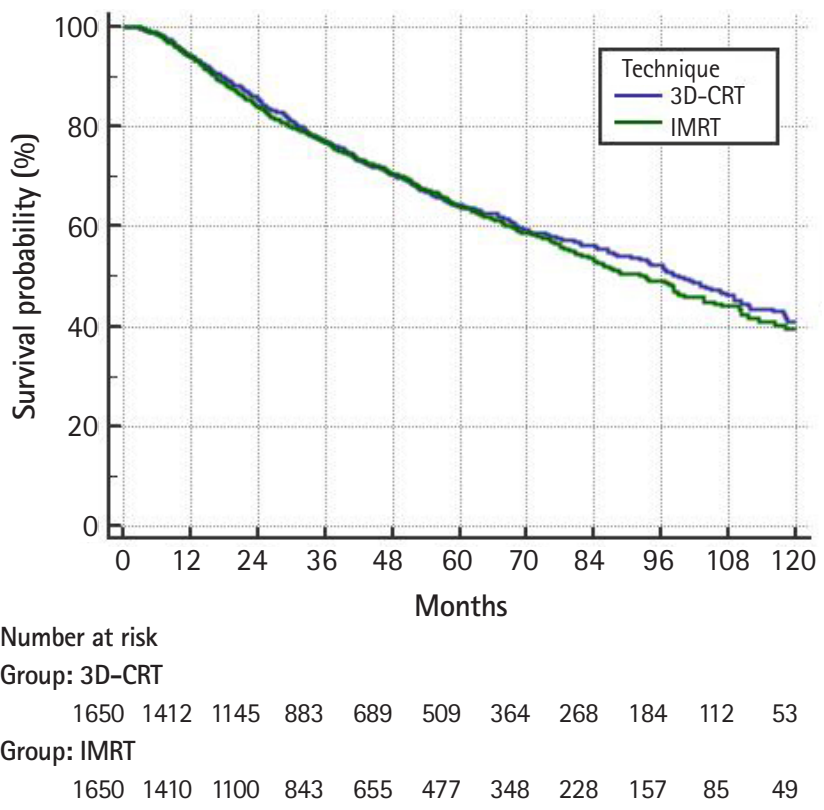

Fig. 3. Propensity matched Kaplan-Meier curve comparing overall survival of three-dimensional conformal radiotherapy (3D-CRT) and intensity-modulated radiation therapy (IMRT). The median survival was 99 months for 3D-CRT and 93 months for IMRT ( $p=0.50)$.

tially indicating other factors suggestive of more aggressive disease and extensive treatment.

As mentioned above, the goal of radiation in early laryngeal cancer is ultimately organ preservation. Current NCCN guidelines recommend either 3D-CRT or IMRT with doses ranging from $63 \mathrm{~Gy}$ at 2.25 Gy per fraction to 66 Gy using 2 Gy per fraction [6]. To that end, randomized trial comparing $60 \mathrm{~Gy}$ in 2 Gy per fraction to $63 \mathrm{~Gy}$ in 2.25 Gy per fraction was conducted by a group from Japan. The results of this trial reported a significant local control benefit of $92 \%$ versus $77 \%$ in favor of 2.25 Gy per fraction [7]. Of note, in that study all patients were essentially treated with 3D-CRT consisting of 2 parallel opposed lateral fields encompassing the larynx in its entirety. Historically, this has represented the standard treatment technique. In our study, $42 \%$ of patients received a hypofractionated regimen, whereas 51\% received a conventionally fractionated ( $<2.25$ Gy per fraction) regimen. In patients receiving IMRT, 29\% received a hypofractionated regimen ( $p$ $<0.001$, independent t-test), with 47\% receiving a convention fractionated regimen. The less than expected use of hypofractionated regimens is likely a reflection of clinical lag time in adopting the hypofractionated schedule since the Japanese study was not published until 2006. For example, 55\% of patients receiving treatment after the year 2009 received the hypofractionated course. Comparatively, the group from the University of Florida 

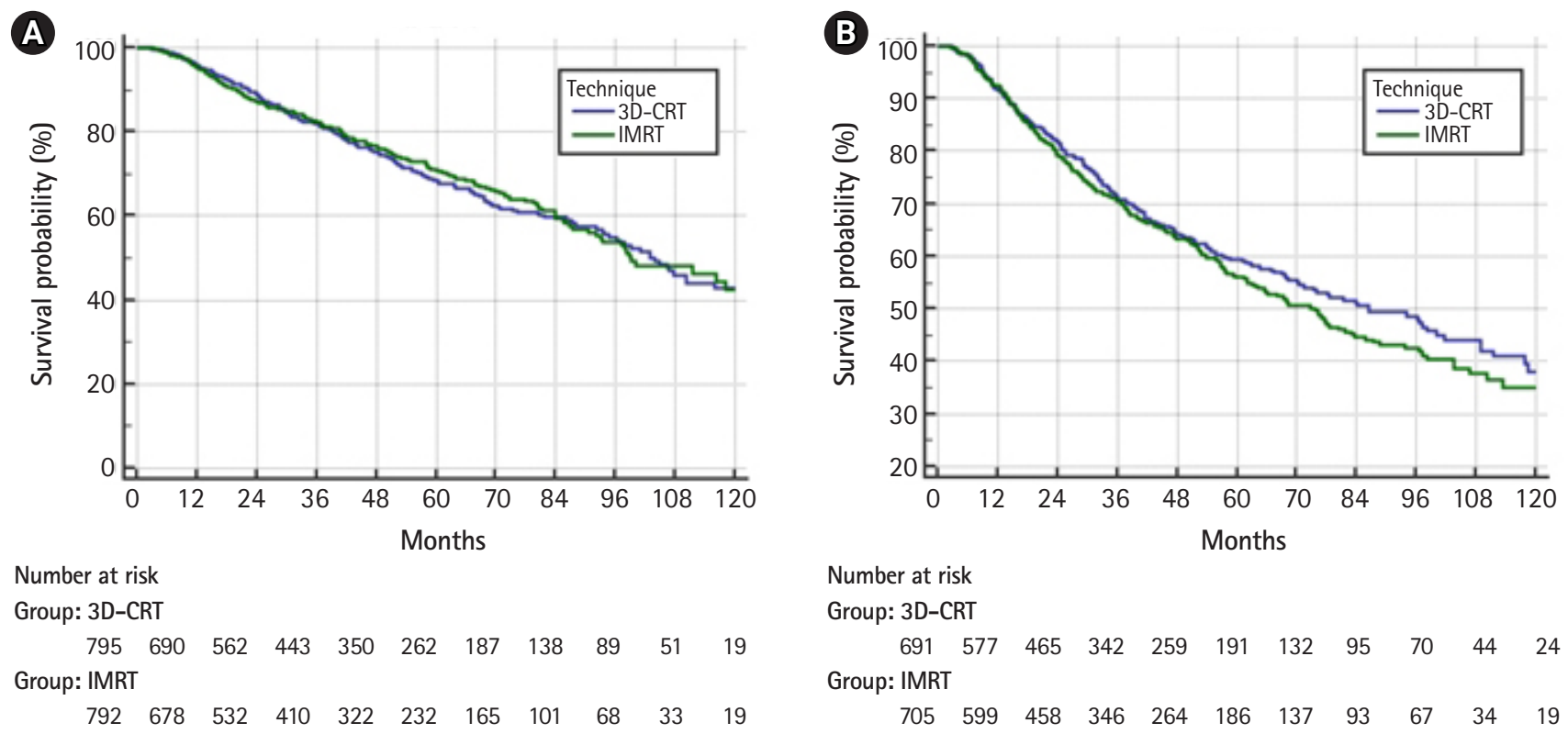

Number at risk

Group: 3D-CRT

$\begin{array}{ccccccccccc}\begin{array}{c}691 \\ \text { Group: IMRT }\end{array} & 577 & 465 & 342 & 259 & 191 & 132 & 95 & 70 & 44 & 24 \\ 705 & 599 & 458 & 346 & 264 & 186 & 137 & 93 & 67 & 34 & 19\end{array}$

Fig. 4. (A) Overall survival for T1 lesions only. The median survival was 99 months for 3D-CRT and 104 months for IMRT ( $p=0.85$ ). (B) Overall survival for T2 lesions only. The median survival was 96 months compared to 86 months for 3D-CRT and IMRT, respectively ( $p=0.25)$. 3D-CRT, three-dimensional conformal radiotherapy; IMRT, intensity-modulated radiation therapy.

presented long-term follow-up of close to 600 patients treated in such a manner, showing local control ranging from $70 \%$ to $94 \%$ depending on T stage [15].

The technique of IMRT was developed and implemented to provide a highly conformal dose of radiation, and spare surrounding organs with the goal of reducing toxicity. In the head and neck region this took the form of sparing major salivary glands to lower the rate of long-term xerostomia [16]. These results and the concept of organ sparing were then extrapolated to early stage carcinoma of the glottic larynx, with the thought of carving dose off of the carotid arteries to prevent development of stenosis and longterm cerebrovascular morbidity [17]. The group from Florida showed that this was a feasible accomplishment by running sample plans on 5 test cases, showing mean doses of $4 \mathrm{~Gy}$ to the carotid artery with IMRT compared to doses as high as 39 Gy using opposed lateral treatment [9]. Additionally, the group from Memorial Sloan Kettering reported on their outcomes comparing 3D-CRT to IMRT, with 48 of 330 patients being treated with the more advanced technique [10]. In this series, the target remained the entire anatomic larynx. Again, there was no difference in 3-year local control rates, both approximating 90\%. To further capitalize on the conformality of IMRT, some institutions have even treated the involved vocal cord only (in T1a patients) [18]. That particular study was completed in the Netherlands and used a unique dose of $3.63 \mathrm{~Gy} \times 16$ fractions to the involved cord in its entirety plus 3-4 $\mathrm{mm}$ of margin to generate the final target. At 2 years, local control was $100 \%$ and there was no serious toxicity.

Of note, our series did not show any difference in survival across the entire cohort which is expected considering laryngectomy is a highly effective form of salvage at time of local failure. It should also be mentioned that IMRT planning is more involved and requires more extensive quality assurance, as indicated by the longer time to initiation of treatment seen here in our analysis. As alluded to above, the highly conformal nature of IMRT would spare dose to surrounding areas, including lymphatics which would otherwise receive close to full dose with 3D-CRT. In theory, patients treated with IMRT could have a higher risk of failure in the neck, leading to the results presented here (although neck failure rates were low in the studies discussed above). Interestingly, our study also showed use of chemotherapy to be indicative of poorer outcome, with no clear indication. Perhaps patients had other factors not captured within the NCDB (bulky tumors, subclinical lymphadenopathy, etc.) leading physicians to include chemotherapy as part of their treatment regimen and thus influencing outcome. Similarly, patients treated in more recent years had worse overall survival, again with no clear explanation. This finding is likely an outlier and merely coincidental.

Our study is not without limitations. As is the case with most NCDB analyses, it is retrospective in nature and can result in a significant selection bias. Also, toxicity is not recorded within the $\mathrm{NCDB}$, which is a detriment as the main goal of IMRT is to reduce toxicity by decreasing dose to surrounding normal structures. Lo- 
cal failure is also not recorded, nor is any type of salvage therapy, which would be important in this setting as rates of salvage laryngectomy would be a key finding.

In conclusion, the rate of IMRT use in early SCC of the glottic larynx has steadily risen over time, although it is still used in a minority of cases. There was no difference in overall survival in this series, with the exception of $\mathrm{T} 2$ patients.

\section{Conflict of Interest}

No potential conflict of interest relevant to this article was reported.

\section{References}

1. Siegel RL, Miller KD, Jemal A. Cancer statistics, 2018. CA Cancer J Clin 2018;68:7-30.

2. Steiner $W$. Results of curative laser microsurgery of laryngeal carcinomas. Am J Otolaryngol 1993;14:116-21.

3. Ambrosch P. The role of laser microsurgery in the treatment of laryngeal cancer. Curr Opin Otolaryngol Head Neck Surg 2007; 15:82-8.

4. Mendenhall WM, Werning JW, Hinerman RW, Amdur RJ, Villaret DB. Management of T1-T2 glottic carcinomas. Cancer 2004; 100:1786-92.

5. American Society of Clinical Oncology, Pfister DG, Laurie SA, et al. American Society of Clinical Oncology clinical practice guideline for the use of larynx-preservation strategies in the treatment of laryngeal cancer. J Clin Oncol 2006;24:3693-704.

6. National Comprehensive Cancer Network. NCCN Guidelines: head and neck cancer (Version 2.2019) [Internet]. Plymouth Meeting, PA: National Comprehensive Cancer Network; 2019 [cited 2020 Feb 5]. Available from: https://www.nccn.org/professionals/physician_gls/default.aspx.

7. Yamazaki H, Nishiyama K, Tanaka E, Koizumi M, Chatani M. Radiotherapy for early glottic carcinoma (T1NOMO): results of prospective randomized study of radiation fraction size and overall treatment time. Int J Radiat Oncol Biol Phys 2006;64:77-82.

8. Bhide SA, Newbold KL, Harrington KJ, Nutting CM. Clinical evaluation of intensity-modulated radiotherapy for head and neck cancers. Br J Radiol 2012;85:487-94.

9. Chera BS, Amdur RJ, Morris CG, Mendenhall WM. Carotid-sparing intensity-modulated radiotherapy for early-stage squamous cell carcinoma of the true vocal cord. Int J Radiat Oncol Biol Phys 2010;77:1380-5.

10. Zumsteg ZS, Riaz N, Jaffery $S$, et al. Carotid sparing intensity-modulated radiation therapy achieves comparable locoregional control to conventional radiotherapy in T1-2N0 laryngeal carcinoma. Oral Oncol 2015;51:716-23.

11. Deyo RA, Cherkin DC, Ciol MA. Adapting a clinical comorbidity index for use with ICD-9-CM administrative databases. J Clin Epidemiol 1992;45:613-9.

12. Cox DR. Regression models and life-tables. J R Stat Soc Series B Stat Methodol 1972;34:187-220.

13. D'Agostino RB Jr. Propensity score methods for bias reduction in the comparison of a treatment to a non-randomized control group. Stat Med 1998;17:2265-81.

14. Kaplan EL, Meier P. Nonparametric estimation from incomplete observations. J Am Stat Assoc 1958;53:457-81.

15. Chera BS, Amdur RJ, Morris CG, Kirwan JM, Mendenhall WM. T1N0 to T2N0 squamous cell carcinoma of the glottic larynx treated with definitive radiotherapy. Int J Radiat Oncol Biol Phys 2010;78:461-6.

16. Eisbruch A, Ten Haken RK, Kim HM, Marsh LH, Ship JA. Dose, volume, and function relationships in parotid salivary glands following conformal and intensity-modulated irradiation of head and neck cancer. Int J Radiat Oncol Biol Phys 1999;45:577-87.

17. Plummer C, Henderson RD, O'Sullivan JD, Read SJ. Ischemic stroke and transient ischemic attack after head and neck radiotherapy: a review. Stroke 2011;42:2410-8.

18. Al-Mamgani A, Kwa SL, Tans L, et al. Single vocal cord irradiation: image guided intensity modulated hypofractionated radiation therapy for T1a Glottic cancer: early clinical results. Int J Radiat Oncol Biol Phys 2015;93:337-43. 